\title{
L'IMAGINATION DE JACQUES DELILLE: ANTECEDENTE DE I SEPOLCRI DE UGO FOSCOLO
}

\author{
Giorgia Marangon \\ Universidad de Málaga
}

\begin{abstract}
RESUMEN
En este artículo se analizan las influencias que ha tenido el poeta francés Jacques Delille con su Imagination sobre el poema I Sepolcri de Ugo Foscolo. Un atento análisis temático y textual de la obra original de Delille con el "Carme" del poeta italiano, pone de manifiesto la, a veces sorprendente, influencia de las temáticas sepulcrales tratadas por el francés en la literatura y poesía no sólo italiana sino europea.

Palabras clave: Foscolo, Delille, italiano, influencia, imitación.

ABSTRACT

This article analyses the influences by the French writer Jacques Delille have had on Ugo Foscolo's poem I Spolcri. A careful thematic and textual analysis of Delille's original work, with the Italian poet's "Carme" clearly showes the sometimes surprising influence of sepulchral themes explored by the French writer, not only in Italian but also in European poetry and literature.

Keyrwords: Foscolo, Dellille, Italian, imitation, influence.
\end{abstract}

En los países de lengua romance la historia de la poesía nocturna y sepulcral presenta unas características particulares. Salvo raras excepciones, todo lo que en estos países se conoce sobre los prototipos del género se reduce a las traducciones francesas que Le Tourneur ofrece de Edward Young, James Hervey y Thomas Gray, que son, a todos los efectos, los precursores de este tipo de poesía ${ }^{1}$.

${ }^{1}$ Young, Hervey y sobre todo Gray, influencian el crecimiento artístico de los autores europeos de habla romance: I. Pindemonte y U. Foscolo en Italia, J. Delille y G. Legouvé en Francia; con sus obras sobre el misterio de la vida y de la muerte, dejaron una huella indeleble sobre los autores posteriores que sobre este género escribieron. P. Van Tieghem, Le Préromanticisme, études d'histoire littéraire européenne, París, Sfelt, 1921, pp. 7-203. 
En Italia este género de poesía, que ve en la obra poética de Ugo Foscolo su máximo exponente, es también una derivación de la gran corriente nocturna y sepulcral inglesa y francesa. Las traducciones de Melchiorre Cesarotti, Giuseppe Torelli y Le Tourneur, que figuran entre las más conocidas, constituyen un conjunto de páginas abiertas sobre el escritorio del poeta italiano ${ }^{3}$ que ve en la escuela sepulcral francesa, cuyos máximos exponentes son Jacques Delille y Gabriel Legouvé, el primer síntoma de una poesía civil.

Antes de la aparición de The Nights y las Meditations among the tombs en la traducción en lengua francesa de Le Tourneur, encontramos pocos textos de gusto sepulcral. Entre los posteriores a la traducción de los ingleses y a las publicaciones de Jacques Delille, que podemos considerar como uno de los más líricos y sublimes poetas sepulcrales franceses, es interesante mencionar Les Tombeaux de Philippe Bridel (1779) y las Méditations sur la Mort, faites dans un cimetière de Bulidon (1782), (Tieghem 1921: 151).

Los debates surgidos en Francia entre 1795 y 1804 sobre la manera de efectuar los enterramientos, así el panorama literario del género sepulcral menor antes mencionado, constituyen el fondo sobre el que empieza a trabajar Jacques Delille ${ }^{4}$. Este autor no hacía más que retomar y traducir en discurso poético

${ }^{2}$ G. Pecchio, Vita di Ugo Foscolo, Lugano, Le Monnier, 1830; G. Chiarini, La vita di Ugo Foscolo, Firenze, Barbèra, 1927; L. Carrer, Vita di Ugo Foscolo, Venezia, Gondoliere, 1842; E. Mandruzzato, Ugo Foscolo, Milano, Rizzoli, 1978; G. Natali, La vita e le opere di Ugo Foscolo, Firenze, Barbèra, 1953; P. Fassano, "Vita e testi: introduzione e una biografia foscoliana", La Rassegna della Letteratura Italiana, 1-2 (1980), pp. 161-78; M. Fubini, Ugo Foscolo, Torino, 1929; A. Marinari, Classicismo, romanticismo e liberalismo nell'età della Restaurazione, en N. Mineo y A. Marinari, Da Foscolo all'età della Restaurazione, Bari, Laterza, 1977, (Letteratura Italiana Laterza), pp. 169-174, y relativa bibliógrafia, pp. 249-250.

${ }^{3}$ V. Di Benedetto, "Lo scrittoio di Ugo Foscolo", a cura de G. Melli, La Rassegna della Letteratura Italiana, X, 3 (1992); V. Cian, "Su una probabile fonte dei Sepolcri foscoliani”, Le Rassegne foscoliane, Il Giornale Storico della Letteratura Italiana, (1921); B. Zumbini, "La poesia sepolcrale straniera e italiana e il carme del Foscolo", La Nuova Antologia, 3. a s, XXIV, XIX (1889); G. Mancorda, Studi foscoliani, Bari, Laterza, 1921, pp. 280 y siguientes.

${ }^{4}$ Nace en Limagne el 22 de junio de 1738, en Aigue-Perse, y muere en París en 1813. Muy admirado por la reina María Antonieta, fue un poeta descriptivo y compuso poemas de gusto clasicista. Entre sus obras más importantes recordamos Les Jardins, L’homme des champs y L'imagination. Véase para una mayor información bibliografiíta: J. Delille, Cuvres choisies, Paris, Firmin-Didot, 1887, pp. 1-11; Dictionnaire des littératures de langue française, a cura de J. P. Beaumarchais, D. Couty y A. Rey, Paris, Bordas, 1987, vol. I, p. 649 ; Grand Dictionnaire 
cuanto en aquellos años se debatía con fervor y fuerza polémica en revistas y periódicos, convirtiendo a Francia en el segundo país, cronológicamente hablando, que se interesó en profundidad por este género literario que en Ugo Foscolo quizás encuentre a su mayor admirador.

No se puede atribuir a Foscolo una lectura atenta y completa de todo el corpus del autor francés en función de la composición de su obra poetica, I Sepolcri', pero un buen conocimiento de esta literatura se puede presumir gracias a su larga estancia en tierra francesa y al testimonio aportado por una carta fechada en Verona el 28 de junio de 1806, y dirigida a Isabella Teotochi Albrizzi ${ }^{6}$, amiga y amante del poeta italiano, en la cual menciona el poema de Delille L'Imagination:

[...] Non vi sgrido punto. Io pure son rimasto scontento dell'Imagination, benché io non abbia letto che i due primi canti, e tutta quella parte del settimo in cui trattasi de'sepolcri`.

Como bien confirma dicha carta, el argumento sepulcral constituye sólo una parte de toda la composición, la séptima, que es sin duda la más importante para el desarrollo de nuestro análisis. L'Imagination ${ }^{8}$, publicada en 1806, anticipa, sin lugar a dudas, el tema, tan apreciado por los italianos y por toda la literatura extranjera del siglo XIX, del canto al valor cívico y político de las tumbas, en mayor medida aún que aquellos a los que se considera padres del tema sepulcral, es decir, los prerrománticos ingleses.

Las tumbas, afirma Delille, no sólo son útiles para las personas consideradas como individuos, sino también para el Estado y para la sociedad en su conjunto; convierten en sagradas las últimas voluntades de los difuntos y unen entre ellas a las generaciones humanas que se van sucediendo en la escena del mundo. Los temas tratados en el séptimo canto ponen en evidencia las formas que

Encyclopédique Larousse, Paris, G. D. E. L., vol. III, 1982, p. 3068 ; La Nuova Enciclopedia Universale Garzanti, Milano, Garzanti, 1982, p. 412.

${ }^{5}$ U. Foscolo, Poesie e Carmi. Poesie-Dei Sepolcri-Poesie Postume-Le Grazie, a cura de F. Pagliai, G. Folena, M. Scotti, en Edizione Nazionale delle opere di Ugo Foscolo, Firenze, Le Monnier, vol. I, 1985; A. Momigliano, "La poesia dei Sepolcri", Il Giornale Storico della Letteratura Italiana, XCIII (1929), p. 170; G. Getto, La composizione dei Sepolcri di Ugo Foscolo, Firenze, Olschki, 1977, p. 134; S. Gamberini, Analisi dei Sepolcri foscoliani, Messina-Firenze, G. D’Anna, 1982.

${ }^{6}$ G. Pizzamiglio, "Ugo Foscolo nel salotto di Isabella Teotochi Albrizzi”, Quaderni Veneti, 2 (1985).

${ }^{7}$ F. S. Orlandini, E. Mayer, Epistolario, Firenze, Le Monnier, 1936, p. 240.

${ }^{8}$ J. Delille, L'Imagination, Poëme, Paris, Ciguet e Michaud, t. I, 1806. 
l'imagination ha generado para suplir la insuficiencia de las leyes y las penas necesarias para gobernar a un pueblo y para inspirarle el amor a la patria y a la obediencia. Se describen ceremonias y celebraciones públicas del culto a los muertos entre pueblos tanto civilizados como salvajes; dedica un largo pasaje a M. Turgot y a la profanación de las tumbas de los hombres ilustres en el cementerio francés de Saint Denis; exalta los monumentos funerarios como símbolos de virtud, amaestramiento y reflexión sobre los peligros que el abandono de tales usos y conceptos puede acarrear.

Mucho de Delille encontramos en los Sepolcri de Foscolo. ¿Realmente el poeta italiano, en la composición de los Sepolcri, se ha visto influenciado por la literatura sepulcral francesa y, en especial manera, por este séptimo canto de L'Imagination? Un atento análisis textual nos facilita la respuesta.

L'Imagination se abre con una apóstrofe dirigida a la antigua civilización griega, a Homero y al culto de la tradición clásica: (vv. 1-6, 19-42), tema éste que desarrolla con gran lirismo y dramatismo Ugo Foscolo en los Sepolcri, donde, evocando los versos de Delille, describe los lugares que han hecho inmortales a personajes como Aquiles, Ayax y Ulises (vv. 201-225, 288-295).

Delille advierte: "L'imagination, me porte dans la Grèce" (Delille 1806: 133). Sabemos en realidad que visitó este país, acompañando hasta Constantinopla a monsieur de Choiseuil-Gouffier, embajador de Francia.

El viaje a Grecia, para Delille, parece ser una fuente inagotable de hermosos versos y recuerdos, gracias al especialísimo guía con el que pudo contar: "Homère m'a guidé dans les champs où fut Troie" (Delille 1806: 133). Se había dado cuenta de que Troya no había cambiado de aspecto desde los tiempos de Homero y que la descripción de las batallas en la Ilíada indicaba con extrema precisión la ubicación de los distintos lugares: promontorios, ríos, valles, colinas, y hasta las tumbas de los guerreros se mostraban a los ojos de los observadores en los lugares que Homero había descrito.

Las danzas de las que fue espectador le recuerdan la imagen de las vírgenes de Esparta: veinte jóvenes, completamente vestidas de blanco, con el cabello perfumado, cantando le hacían volver a la memoria el sonido melodioso de la lengua sagrada para Homero y los dioses. Aún respiraba la libertad de los antiguos héroes, y las sombras de Helena y Héctor seguían cubriendo los antiguos palacios y templos: estas son las sensaciones que Delille nos transmite con sus versos y que Foscolo retoma en su poesía, dando vida a imágenes y sonidos que reevocan tiempos lejanos. Una vez más, es el "sacro vate" (Foscolo 1985: 133) quien hace eternos, con su poesía, a los griegos vencedores, sin olvidar 
a Héctor, "onore di pianti" (Foscolo 1985: 133), que mereció gloria y fama como defensor de la patria.

Delille, como luego Foscolo, se detiene a analizar el aspecto mítico de la Grecia homérica, rememorando con imágenes fuertes antiguas sugestiones; guiado por Homero, Delille recorre los campos de Troya, donde los restos de los templos y de los monumentos testimonian el antiguo esplendor. Entre aquellas murallas olvidadas se percibe aún la melodía de cantos y bailes, y allí donde se reconoce todavía la sombra de los antiguos héroes (Helena y Héctor), la lengua sagrada para Homero y los dioses nunca morirá. Foscolo, al sonido melodioso de cantos y bailes, preferirá el "suon di tube" (Foscolo 1985: 131) y el "incalzar di cavalli accorrenti scalpitanti su gli elmi a' moribondi” (Foscolo 1985: 131), sin olvidar "pianto, ed inni, e delle Parche il canto" (Foscolo 1985: 131). Por medio de estos versos nos hace remontarnos a otros tiempos y, "finchè il sole risplenderà su le sciagure umane" (Foscolo 1985: 133), tales memoria seguirán siendo eternas para la humanidad.

Claras son las semejanzas entre los dos autores, y clara es la influencia del francés sobre Foscolo, y más evidente aún resulta la imitación temática:

$$
\begin{aligned}
& \text { J'ai médité long-temps, assis sur les tombeaux; } \\
& \text { non pas pour y chercher, dans ma mélancolie, } \\
& \text { le secret de la mort mais celui de la vie. } \\
& \text { (L'Imagination, vv. 164-166). }
\end{aligned}
$$

En estos versos Delille contrapone su forma de considerar las tumbas a la de los ingleses y alemanes que, creyendo en una vida después de la muerte, no atribuían valor a las cosas terrenales. Delille, en cambio, medita sobre los efectos positivos que los monumentos funerarios suscitan en quienes siguen vivos. Y aún más, describiendo la visita a un cementerio, evidencia cómo la corrispondenza d'amorosi sensi entre los vivos y los muertos se mantiene viva justo gracias a la pétrea lápida sepulcral, ante la cual los vivos lloran al amigo desaparecido, creando de esta manera el mencionado sentimiento, que es uno de los elementos constantes en el desarrollo de la temática sepulcral foscoliana:

Aucun ne se méprend, chacun connaît la pierre où tout ce qu'il aima repose sur la terre, et la tertre modeste où git l'humble cercueil, et la croix funéraire, et l'if ami du deuil, qui, protégeant les morts de son feuillage sombre, a l'ombre des tombeaux aime à mêler son ombre. (L'Imagination, vv. 313-318). 
Non vive ei forse anche sotterra, quando

gli sarà muta l'armonia del giorno, se può destarla con soavi cure nella mente dei suoi? Celeste è questa corrispondenza d'amorosi sensi, celeste dote è negli umani; e spesso per lei si vive con l'amico estinto, e l'estinto con noi, se pia la terra che lo raccolse infante e lo nutriva, nel suo grembo materno ultimo asilo porgendo, sacre le reliquie renda dall'insultar de' nembi e dal profano piede del vulgo, e serbi un sasso il nome, e di fiori odorata arbore amica le ceneri di molli ombre consoli. (Dei Sepolcri, vv. 26-40).

En la gloria eterna radica el verdadero sentido de la vida y, de ahí, la esperanza de sobrevivir también bajo tierra en el recuerdo de los que siguen en vida.

La tierra es vista como madre, como vuelta al útero materno, pero también como receptáculo de muerte; muerte por tanto entendida como vida, como forma de consecución de una vida auténtica. Y esto porque quien muere tiene la ilusión de no morir del todo, sino de volver a vivir en la memoria de los amigos: entre los muertos y los vivos existe, de hecho, una cierta corrispondenza d'amorosi sensi, y "spesso per lei si vive con l'amico estinto, e l'estinto con noi" (Foscolo 1985: 126). La tumba, en conclusión no es útil para quien muere, sino que nutre unos valores para los vivos: ofrece, en efecto, la ilusión de que el fallecido vuelve a revivir en quien aporta un signo tangible de unión: una flor, una simple visita a la tumba, y crea de reflejo en el poeta la convicción de que también su tumba, algún día, será objeto de amorevoli cure.

La unión de la vida y la muerte, a la que se refiere Delille, es la misma que Foscolo repropone en los primeros versos de su poema:

Regardez ces débris dispersés par les vents: croyez-vous tous ces morts étrangers aux vivants? Non: d'un tendre intérêt sources toujours fécondes, les tombeaux sont placés aux confins des deux mondes; rendez-vous triste et cher, où, confondant leurs vœux, la vie et le trépas correspondent entr'eux.

Ceux que vous croyez morts vivent dans vos hommages; 
vous conservez leurs noms, vous gardez leurs images;

(L'Imagination, vv. 167-174).

All'ombra de' cipressi e dentro l'urne

confortate di pianto è forse il sonno

della morte men duro?

(Dei Sepolcri, vv. 1-3).

En los siguientes versos vemos cómo Delille siente cercano el tema de la tumba, vista como elemento de recomposición de afectos familiares, que como sabemos es uno de los argumentos cardinales del poema foscoliano. Lloran los familiares la muerte del hijo, y la madre, gimiendo, vierte leche sobre la tumba, símbolo de vida y lágrimas, símbolo de muerte:

Dans ses marques de deuil quel sentiment profond!

Tandis que sur sa main posant son triste front, l'époux morne et pensif pleure un fils qu'il adore, la mère en gémissant vient le nourrir encore; et sur la tombe où gît l'objet de ses douleurs, elle verse en silence et son lait et ses pleurs. (L'Imagination, vv. 183-188).

Rapian gli amici una favilla al Sole a illuminar la sotterranea notte, perché gli occhi dell'uom cercan morendo il Sole; e tutti l'ultimo sospiro mandano i petti alla fuggente luce. Le fontane versando acque lustrali amaranti educavano e viole su la funebre zolla; e chi sedea a libar latte e a raccontar sue pene ai cari estinti, una fragranza intorno sentìa qual d'aura de' beati Elìsi.

(Dei Sepolcri, vv. 119-129).

La asonancia sole/notte subraya la coincidencia en el sepulcro de luz y tinieblas, de vida y muerte; la tumba es vista como lugar de reconciliación de los afectos familiares, que se reconduce a la imagen del vivo sentado sobre la tumba 
conversando con el difunto. Inevitable aquí la referencia al soneto In morte del fratello Giovanni (Foscolo 1985: 110-111)'.

Obsérvense en los Sepolcri el latinismo "libar" y el sustantivo "latte", símbolo de vida, análogo al "lait" del verso 188 de L'Imagination: "Elle verse en silence et son lait et ses pleurs". Versos, los foscolianos (126-129) que recogen una sugestión de Tibulo: "Illius ad tumulum fugiam supplexque sedebo, / et mea cum muto fata querar cinere" ${ }^{" 10}$.

A través de la tumba el hombre cultiva la ilusión de poder sobrevivir en el recuerdo de las personas queridas: es el canal de relación afectiva entre vivos y muertos, gracias al cual el difunto, vuelto al seno materno de la naturaleza protectora, gracias a esa tumba que conserva su nombre, sigue viviendo en la piedad de los seres queridos.

El sepulcro, como lazo de afectos familiares, es la imagen de esa corrispondenza d'amorosi sensi que une a muertos y vivos y mantiene viva en estos la ilusión de poder conversar aún con ellos y contarles sus propias penas.

Evidentes resultan, ya en esta fase, las influencias de la literatura francesa en la italiana, como resulta claro a través de la comparación que sigue de los versos del poema foscoliano y los del poema de Delille. Obsérvese, en efecto, como los siguientes versos franceses son casi retomados y traducidos al italiano por Foscolo:

Si j'entre en ces dépôts des monuments antiques, ces urnes, ces trépieds, ces bronzes magnifiques, n'égalent pas pour moi ces vases de douleurs où l'amitié versait et recueillait ses pleurs.

(L'Imagination, vv. 225-228).

[...] Ma cipressi e cedri di puri effluvi i zefiri impregnando perenne verde protendean su l'urne per memoria perenne, e preziosi

9 Un dì s'io non andrò sempre fuggendo

Di gente in gente, me vedrai seduto

Sulla tua pietra, o fratel mio, gemendo

Il fior de' tuoi gentili anni caduto.

(In morte del fratello Giovanni, vv. 1-4)

${ }^{10}$ TIBULLO, Elegie, II, 6, Milano, Sonzogno, 1902. 
vasi accogliean le lagrime votive.

(Dei Sepolcri, vv. 114-118).

Ces vases de douleurs où l'amitié versait et recueillait ses pleurs non son sino las preciosas ánforas que recogían, según Foscolo, las lágrimas votivas. Los anticuarios de la primera parte del siglo XIX, como se sabe, pensaban que las ánforas encontradas en las tumbas estaban destinadas a recoger las lágrimas vertidas para llorar la muerte del difunto. La arqueología moderna, en cambio, ha constatado que tales ánforas llenas de aceites balsámicos y esencias perfumadas formaban parte del ajuar funerario que acompañaba al difunto en la que se creía que sería su vida ultraterrena. Este error se encuentra en ambos autores; una razón más para reconocer en Foscolo la evidente influencia de Delille, y en este caso concreto de sus "vases de douleurs" (Delille 1806: 143).

El largo paréntesis que sigue sirve para delinear la idea de Delille sobre la conservación y el respeto de las tumbas y sobre lo mucho que es útil honrarlas; es ejemplar al respecto el siguiente verso: "Le respect pour les morts gouverne encore la vie" (Delille 1806: 146). Y termina recordando los ultrajes propinados a ilustres personajes en París. Es suficiente un nombre como ejemplo de todos: el del vizconde de Turenne, cuyo sepulcro fue violado por hombres sin honor y sin respeto hacia el lugar sagrado: "Du vengeur de l'état le repos est troublé, / Ses honneurs sont détruits, son cercueil violé!" (Delille 1806: 166). El estado de ánimo de Delille estaba ya turbado, como testimonian los versos anteriores a los del vizconde de Turenne, referidos a otra muerte ilustre, la del amigo Turgot ${ }^{11}$. "D'un mal héréditaire, ainsi que tes vertus, / tu meurs, mais tes bienfaits vivent où tu n'es plus" (Delille 1806 : 151); "Dans la nuit du tombeau tu dors en paix, et moi, / je pleure ici, tout Seúl, sur la France e sur toi” Delille 1806 : 151).

Pero véanse los versos a los que me refiero:

Protéger les tombeaux, c'est honorer les morts;

et ce culte sublime, en consacrant leurs corps,

maintenant leurs volontés, impose au sacrilège

qui, bravant du trépas l'auguste privilège,

outrageant et la tombe, et la terre, et les cieux,

de la mort libérale ose tromper les vœux.

(L'Imagination, vv. 263-268).

${ }^{11}$ Filósofo sensista francés (1727-1781), economista, colaborador de la Enciclopedia, miembro del Tribunal de Cuentas de Francia, fue obligado a dimitir por haber atacado los intereses de la nobleza, el alto clero y las grandes finanzas bajo el reinado de Luis XVI. 
Mais du sein de la nuit et du fond du tombeau, un cri religeux, le cri de la nature, vous dit: «Pleurez, priez sur cette sépulture; vos parents, vos amis dorment dans ce séjour, monument vénérable et de deuil et d'amour. Ces êtres consacrés par les devoirs suprêmes, honorez-les pour eux, pour l'état, pour vous mêmes». Ainsi le dogme saint de l'immortalié recommande notre ombre à la postérité; ainsi prêtant sa force au saint nœud qui nous lie, le respect pour les morts gouverne encor la vie. (L'Imagination, vv. 280-290).

Les morts n'ont plus d'amis; mais si nos froids hommages des antiques douleurs dédaignent les usages, o vous que j'ai perdus, qu'enferme le cercueil, ah! lisez dans mon âme, et voyez-y mon deuil. Toi surtout, toi, Turgot, que j'aimai dès l'enfance, toi, l'ami des vertus, des arts et de la France, cœur noble et généreux, je n'oublîrai jamais Que tu daignas sourire à mes premiers essais, que tu vins me chercher dans mon humble fortune, que tu formas mon goût, aidas mon infortune: d'un mal héréditaire, ainsi que tes vertus, tu meurs; mais tes bienfaits vivent où tu n'es plus. Ces écrits qu'en mourant me légua tendresse, j'en fais ma volupté, mon orgueil, ma richesse. Hélas! le ciel jaloux te ravit à mon cœur, trop tôt pour tes amis, mais non pour ton bonheur: tu n'as point vu les maux de ma triste patrie, le sang qu'elle a versé, le joug qui l'a fletrie; dans la nuit du tombeau tu dors en paix, et moi, je pleure ici, tout seul, sur la France et sur toi. Des malheureux humains cruelle destinée! A souffrir, à mourir leur race est condamnée; de l'indigent surtout tel est le triste sort: le berceau, la douleur, le travail et la mort. (L'Imagination, vv. 381-404).

Mais pourquoi m'y cacher les mânes de Turenne? 
Leur cendre assez long-temps s'honora de la sienne.

Ah! piusse au moins son corps, dans ce caveau sacré, reposer toujours cher et toujours révéré!

Mais que veut ce concours et ce peuple en furie?

O forfait exécrable! ô honte! ô barbarie!

Du vengeur de l'état le repos est troublé,

Ses honneurs sont détruits, son cercueil violè!

Sans respect du lieu saint, des ombres sèpulcrales

on arrache à la mort ses dépouilles royales,

on brise leur couronne, on ouvre leurs tombeaux;

de sacrilège mains dispersent leurs lambeaux.

(L'Imagination, vv. 721-732).

La veracidad y el lirismo de los versos franceses cautivaron la atención y la curiosidad de Foscolo que, retomando la temática de Delille, desarrolla el argumento llevándolo a tierra italiana.

También en Foscolo la piedad y el dolor, que, a diferencia de Delille, encuentran siempre expresión en las figuras femeninas, son los temas portantes de todo el poema, que encuentra su apogeo en la victoria del hombre sobre el olvido, y en la capacidad que tiene la tumba de instaurar una comunicación emotiva entre los muertos y los vivos.

Presérvense los restos mortales del difunto del ultraje de los elementos atmosféricos y del pie profanador del vulgo; Foscolo antropomorfiza el paisaje sepulcral envolviéndolo con matices afectivos:

[...] sacre le reliquie renda

dall'insultar de' nembi e dal profano

piede del vulgo, e serbi un sasso il nome,

e di fiori odorata arbore amica

le ceneri di molli ombre consoli.

(Dei Sepolcri, vv. 36-40).

A través del ejemplo consolador de la tumba del amigo Turgot, "[...] je n'oublîrai jamais / Que tu daignas sourire à mes premiers essais" Delille 1806: 151), Delille pone de relieve un inquietante problema que afecta a Francia durante el período postrevolucionario: el de la profanación de las tumbas.

En el episodio del vizconde Turenne se transparenta toda la amargura y el enojo del autor, que refleja el de todo un pueblo, de una nación. Así hace también Foscolo, demostrando haber leído la obra de Delille. Cambian los personajes y la motivación histórica, pero la sustancia y los resultados son los mismos. Rabia y enojo se plasman en los versos de Foscolo, no por la 
profanación de una tumba, sino por los efectos que el Edicto napoleónico de Saint Cloud ha tenido sobre la tumba del poeta y amigo Parini:

Pur nuova legge impone oggi i sepolcri

fuor de' guardi pietosi, e il nome a' morti contende. E senza tomba giace il tuo sacerdote, o Talia, che a te cantando nel suo povero tetto educò un lauro con lungo amore, e t'appendea corone; e tu gli ornavi del tuo riso i canti che il lombardo pungean Sardànapalo, cui solo è caro il muggito de'buoi che dagli antri abdüani e dal Ticino lo fan d'ozi beato e di vivande. O bella Musa, ove sei tu? Non sento spirar l'ambrosia, indizio del tuo nume, fra queste piante ov'io siedo e sospiro il mio tetto materno. E tu venivi e sorridevi a lui sotto quel tiglio ch'or con dimesse frondi va fremendo perché non copre, o Dea, l'urna del vecchio cui già di calma era cortese e d'ombre. forse tu fra plebei tumuli guardi vagolando, ove dorma il sacro capo del tuo Parini? A lui non ombre pose tra le sue mura la città, lasciva d'evirati cantori allettatrice, non pietra, non parola; e forse l'ossa col mozzo capo gli insanguina il ladro che lasciò sul patibolo i delitti.

(Dei Sepolcri, vv. 51-77).

Turgot, Turenne y Parini son los ilustres personajes que Delille y Foscolo han elegido para expresar su desacuerdo y la vergüenza que caracteriza al momento histórico que viven.

El sepulcro como signo de gloria es el último tema de la comparación entre L'Imagination y el poema foscoliano. Las tumbas de los grandes, en las que se reconoce el espíritu de un pueblo, permiten hacer revivir en aquella grandeza pasada un auspicio de futuro rescate. Este tema, que pone de relieve el valor civil de la tumba es nuevo con respecto a la tradición sepulcral anterior; a través de los 
versos de Delille llega a Foscolo, que lo traduce con sublime lirismo en la poesía que eleva a eternas la gloria de la estirpe humana.

Que dis-je ils ont pour nous le bienfait de l'exemple; du sein de leurs tombeaux, comme du fond d'un temple, sort l'oracle du Dieu dont il est habité.

la mort nous entretient de l'immortalité, et le nom de héros que la patrie adore, ce nom cher aux vertus, nous les commande encore. (L'Imagination, vv. 673-678).

les tombeaux d'un héros, d'un poète, d'un sage, a l'œil religeux s'offraient à chaque pas; le grand jour en chassait les ombres du trépas. Mollement inclinés sur ces mânes cèlèbres, des arbres leur prêtaient de plus douces ténèbres; l'olivier cher aux morts, symbole de la paix, les lauriers trionphants mariés aux cyprès, ombrageaient les vertus, les arts ou la victoire. On croyait parcourrir les jardins de la gloire; (L'Imagination, vv. 703-711).

Ah! laissez, rélé gués dans leurs caveaux pompeux, sous le marbre imposteur qui flatte encor leurs ombres, tous ces rois fainéans qui, sous ces voûtes sombres, ont changé de sommeil, et qu'a jetés le sort du néant de leur vie au néant de la mort. (L'Imagination, vv. 716-720).

Y he aquí los versos foscolianos:

A egregie cose il forte animo accendono l'urne de'forti, o Pindemonte; e bella e santa fanno al peregrin la terra che le ricetta.

(Dei Sepolcri, vv. 151-154).

No sólo, pues, las tumbas de los grandes personajes incitan a los hombres fuertes, sino que convierten también en sagrada la tierra que las acoge. Florencia puede considerarse feliz, más que por su belleza real, por el hecho de dar acogida en la iglesia de Santa Croce a las tumbas de grandes hombres como Maquiavelo, Galileo y Miguel Ángel: 
Con questi grandi abita eterno: e l'ossa frèmono amor di patria. Ah sì! da quella religiosa pace un Nume parla: e nutria contro a' Persi in Maratona, ove Atene sacrò tombe a' suoi prodi, la virtù greca e l'ira.

(Dei Sepolcri, vv. 196-201).

También los restos de Alfieri reposan en la iglesia de Santa Croce; sus huesos "fremono" (Foscolo 1985: 130) puesto que vive, seguramente más que el "dotto e il ricco ed il patrizio vulgo" (Foscolo 1985: 129), cuya vida no era distinta de la muerte, justo como en el caso de los reyes de los que habla Delille: "Ah! laissez, rélé gués dans leurs caveaux pompeux, sous les marbre imposteur qui flatte encor leurs ombres, tous ces rois fainéans qui, sous ces voûtés sombres, ont changé de sommeil, et qu'a jetés le sort du néant de leur vie au néant de la mort" (Delille 1806: 164). De ahí la neta contraposición con los versos de los Sepolcri que acabamos de mencionar, referidos a Alfieri:

Già il dotto e il ricco ed il patrizio vulgo,

decoro e mente al bello italo regno,

nelle adulate regge ha sepoltura

già vivo, e i stemmi unica laude.

(Dei Sepolcri, vv. 142-145).

A través del análisis comparativo de las composiciones se observa cómo las temáticas del poema de Delille están presentes en el poema foscoliano en modo tan evidente y significativo que las reflexiones de Foscolo relativas a los diferentes momentos del argumento sepulcral pierden buena parte de la frescura original. Son claras las referencias temáticas de Foscolo frente a Delille, excluyendo el último tema tratado en los Sepolcri, el de las tumbas de los héroes que, gracias al canto de los poetas, derrotan al silencio de los siglos convirtiéndose en eternas en la memoria de los hombres. Tema éste innovador con respecto a la literatura de la época, que eleva al autor italiano respecto a cuantos habían tratado anteriormente el tema sepulcral:

E me che i tempi ed il desì d'onore

fan per diversa gente ir fuggivo,

me ad evocar gli eroi chiamin le Muse

del mortale pensiero animatrici.

Siedon custodi de'sepolcri, e quando

il tempo con sue fredde ale vi spazza 
fin le rovine, le Pimplèe fan lieti di lor canto i deserti, e l'armonia vince di mille secoli il silenzio. (Dei Sepolcri, vv. 226-234).

De elevada densidad semántica son el adjetivo "diversa", para indicar el tema de la lejanía de la patria, del exilio, subrayado por la expresión "ir fugitivo", reconducibles, el primero, al verso 9 del soneto $A$ Zacinto, el segundo al soneto In morte del fratello Giovanni.

Inspirado por las Musas, el poeta canta a los héroes y, celebrando su memoria, la transmite y la conserva gloriosa a través de la poesía, derrotando incluso a la acción destructora del tiempo y del "silenzio" (Foscolo 1985: 234) de la muerte que todo lo anula menos la voz de la poesía.

Jacques Delille y Ugo Foscolo, dos grandes y resonantes nombres de la literatura europea, dejan, con el tratamiento lírico de estos temas, una huella indeleble de su trabajo en el recuerdo de la posteridad. Y en los Sepolcri de Foscolo se confirman, como hipotizábamos al principio, unos matices de musicalidad y color, una capacidad descriptiva y un tono lírico que nos remiten a la poesia sepulcral europea, en especial la francesa, anterior a la publicación del poema foscoliano. Tenía toda la razón a este respecto Giovanni Getto cuando al analizar el tema del poema foscoliano sostenía que «agiva sul nostro poeta una suggestione, o addirittura una specie di autorizzazione, derivate da alcune opere della letteratura sepolcrale inglese e francese, largamente diffuse in Italia» (Getto 1977: 134).

Giorgia Marangon

Fecha de recepción: 18/07/2006

giorgiamarangon@hotmail.com

Fecha de aceptación:07/09/2006

Universidad de Málaga

Facultad de Filosofía y Letras

Dpto. de Filología Española I y Románica (Área de italiano)

Campus de Teatinos, 29071 Málaga (España) 